Ngoài ra CRP cao, một dấu ấn của viêm phổi bội nhiễm cũng tăng. Gianniki và CS [6] nhận thấy $38 \%$ trẻ mắc sới có biến chứng có CRP trong máu cao $(>20 \mathrm{mg} / \mathrm{L})$ so với $14 \%$ ở trẻ mắc sởi không biến chứng $(p<0,001)$. Trong nghiên cứu chúng tôi không tiêm chủng sởi và CRP máu tăng là hai yếu tố liên quan đến sởi có biến chứng. Ngoài ra các trẻ mắc sởi nhập viện có nôn ói cũng là một yếu tố độc lập có liên quan đến sởi có biến chứng.

Giới hạn của nghiên cứu này là nghiên cứu hồi cứu tại một bệnh viện nên không phản ảnh toàn thể các ca mắc sởi tại thành phố Cần Thơ, hơn nữa số trường hợp được làm xét nghiệm IgM không nhiều, tuy nhiên nghiên cứu này cho thấy hầu hết các trường hợp sởi có biến chứng đều ở những trẻ chưa được tiêm chủng sởi.

\section{KẾT LUÂN}

Trong nghiên cứu của chúng tôi bệnh sởi thường xảy ra ở trẻ nhỏ dưới 12 tháng tuổi, đa số chưa được chủng ngừa sởi. Các triệu chứng và dấu hiệu lâm sàng hay gặp gồm sốt $(100 \%)$, phát ban $(100 \%)$, dấu Koplik $(57 \%)$, ho, chảy mũi, viêm kết mạc và nôn ói. Biến chứng thường gặp nhất là viêm phổi $(21,5 \%)$ và viêm dạ dày ruột $(22,9)$. Không tiêm chủng, CRP trong máu tăng và có triệu chứng nôn ói là các yếu tố độc lập có liên quan đến bệnh sởi có biến chứng.

TÀI LIỆU THAM KHẢO
1. Phạm Thị Thu Hà và Đỗ Văn Dũng (2004), Đăc điểm lâm sàng bệnh sởi ở trẻ em TP Hồ Chí Minh sau khi thức hiện chương trình tiêm chủng mở rộng, Tạp chí Y học TP. Hồ Chí Minh, 8(1), tr. 6-8.

2. Do ĹP, Van TTT, Nguyen DTM, et al. (2021) Epidemiological and molecular characteristics of a measles outbreak in northern Vietnam, 2013-2014. J Clin Virol;139:104840.

3. Kien VD, Van Minh H, Giang KB, et al (2017) Trends in childhood measles vaccination highlight socioeconomic inequalities in Vietnam. Int J Public Health. 62(Suppl 1):41-49.

4. Marufu $T$, Siziya $S$, Murugasampillay $S$, et al. (1997). Measles complications: the importance of their management in reducing mortality attributed to measles. Cent Afr J Med.;43(6):162-5.

5. Marufu T, Siziya S, Tshimanga M, et al. (2001) Factors associated with measles complications in Gweru, Zimbabwe. East Afr Med J.;78(3):135-8.

6. Gianniki $M$, Siahanidou $T$, Botsa $E$, et al. (2018) Measles epidemic in pediatric population in Greece during 2017-2018: Epidemiological, clinical characteristics and outcomes. PLoS One. 6(1):e0245512.

7. Javed N, Saqib MAN, Hassan Bullo MM, et al. (2019) Seroprevalence of transplacentally acquired Measles antibodies in unvaccinated infants at nine months of age and its relation to the feeding practices. BMC Infect Dis.;19(1):587.

8. Kondova IT, Milenkovic Z, Marinkovic SP, et al. (2013) Measles outbreak in Macedonia: epidemiological, clinical and laboratory findings and identification of susceptible cohorts. PLOS One.; 8(9):e74754.

9. Cherry JD, Zahn M. (2018) Clinical Characteristics of Measles in Previously Vaccinated and Unvaccinated Patients in California. Clin Infect Dis.; 67(9):1315-1319.

\title{
NĂNG LỰC QUẢN LÝ CỦA CÁC ĐIỀU DƯỡNG TRƯởNG KHOA LÂM SÀNG CỦA MộT SỐ BỆNH VIÊ̂N CÔNG LÂPP TUYẾN TỈNH LÀO CAI, 2020
}

\section{Nguyễn Ngọc Bích ${ }^{1}$, Lù Tà Phìn ${ }^{2}$}

\section{TÓM TẮT}

Năng lực quản lý của điều dưỡng trưởng là một yếu tố quan trọng để tận dụng mọi nguồn lực tại khọa và bệnh viện để phục vụ và chăm sóc người bệnh. Nghiển cứu mô tả nắng lực quản lý của điêuu dưỡng trưởng các khoa lâm tại các bệnh viện công lập tuyến tỉnh Lào Cai được triển khai năm 2020.Thiết kể nghiên cứu cắt ngang thực hiện tại 05 Bệnh viện tuyến tỉnh của tỉnh Lào Cai từ tháng $6 / 2020-11 / 2020$. Số liệu định lượng thu thập từ bộ câu hỏi phát vấn 54 cán bộ y tế là điêu dưỡng trưởng các khoa lâm sàng, năng

\section{${ }^{1}$ Trường Đại học Y tế công cộng}

²Bênh viện đa khoa tỉnh Lào Cai

Chịu trách nhiệm chính: Nguyễn Ngọc Bích

Email: nnb@huph.edu.vn

Ngày nhận bài: 17.5 .2021

Ngày phản biên khoa họ: 12.5 .2021

Ngày duyệt bài: 18.5 .2021 lực quản lý được đánh giá dựa trên mức đô tư tin khi thực hiện công việc, nghiên cứu cũng đã tiến hành phỏng vấn sâu trển các điều dưỡng trưởng.Kết quả nghiên cứu cho thấy Tỷ lệ điều dưỡng trưởng khoa đủ năng lực quản lý chung vẫn ở mức trung bình là $57,4 \%$. Nghiên cứu khuyến nghị cần tiếp tục đào tạo bồi dưỡng về kiến thức và kỹ năng quản lý điểu dưỡng đồng thời có các hình thức giám sát hỗ trợ.

Tư khoá: quản lý, năng lực, điêuu dưỡng trưởng, bệnh viện

\section{SUMMARY \\ MANAGEMENT CAPACITY OF CHIEF NURSES AT SOME PROVINCIAL HOSPITAL IN LAO CAI, 2020}

Management capacity is one of the most important features in maximizing hospital resources toward good services for patients. This study was conducted in 2020 to investigate the situation of knowledge $s$ on 
management of chief nurses of provincial hospital in Lao Cai. Cross - sectional study was conducted in 54 chief nurses of five provincial in Lao Cai using self administired structured questionnaire and in-dept interviews. Management capacity was assessed based on their confident while practicing. Results show that prevalence of chief nurse who met general management requirements was57.4\%. It was recommended that continuous training was needed, and the hospitals should also provide supportive supervision for chief nurses on management.

Keywords: management, capacity, chief nurse, hospital

\section{I. ĐẠT VẤN ĐỀ}

Chuẩn năng lực cơ bản Điều dưỡng Việt Nam đã được Bộ $Y$ tế ban hành trong đó nêu ra những tiêu chuẩn thuộc ba lĩnh vực là: Năng lực thực hành; Năng lực quản lý và phát triển nghề nghiệp; Năng lực hành nghề theo pháp luật và Đạo đức nghề nghiệp(2).

Quản lý nói chung và quản lý điều dưỡng là một nghệ thuật về việc vận dụng tất cả các nguồn lực sẵn có để hoàn thành nhiệm vụ đã giao đúng thời gian và hiệu quả. Trong quản lý điêu dưỡng, Điều dưỡng trưởng khoa (ĐDTK) là một trong những khâu cơ bản được sử dụng để đạt được chất lượng chăm sóc người bệnh của một khoa tại một đơn vị và thông qua công tác quản lý, người Điều dưỡng trưởng tạo ra một môi trường trong đó tất cả các điều dưỡng phát huy tối đa khả năng của mình để đạt đến mục đích chăm sóc người bệnh(3).

Năng lực quản lý của điều dưỡng trưởng khoa liên quan chặt chẽ đến chất lượng công việc của điều dưỡng trong khoa, thiếu năng lực sẽ ảnh hưởng đến chất lượng chăm sóc, hạn chế hoàn thành nhiệm vụ của người $Đ D$ theo quy định(4).

Nghiên cứu được tiến hành với mục tiêu tìm hiểu năng lực quản lý của điều dưỡng trưởng các khoa lâm sàng tại một số bệnh viện tuyến tỉnh của Lào Cai.

\section{II. ĐỐI TƯợNG VÀ PHƯƠNG PHÁP NGHIÊN CỨU}

2.1. Đối tượng nghiên cứu. Điều dưỡng trưởng các khoa lâm sànglàm việc tại các bệnh viện tuyến tỉnh của Lào Cai.

\subsection{Thời gian và địa điểm nghiên cứu}

Thời gian nghiên cứu: Từ tháng 06 /2020 đến tháng 9/2020. Các Bệnh viện tuyến tỉnh của tỉnh Lào Cai, bao gồm 05 bệnh viện gồm:
(1) Bệnh viện Đa khoa tỉnh
(2)Bênh viên Sản nhi
(3)Bểnh viện Nội tiết
(4)Bểnh viển y học cổ truyền
(5)Bệnh viện Phục hồi chức năng

2.3. Thiết kế nghiên cứu.Nghiên cứu cắt ngang, kết hợp định lượng và định tính.

2.4. Cỡ mấu và phương pháp chọn mẫu

2.4.1. Nghiên cứu định lượng

- Chọn mâuu toàn bộ điều dưỡng trưởng khoa lâm sàng tại 05 bệnh viện tuyến tỉnh theo danh sách được báo cáo của Sở Y tế tỉnh Lào Cai.

- Thực tế nghiên cứu đã tiến hành thu thập số liệu 54 điều dưỡng trưởng đang công tác tại các khoa lâm sàng của 05 bệnh viện tuyến tỉnh.

2.4.2. Nghiên cứu định tính. Sử dụng phương pháp chọn mấu chủ đích, cụ thể như sau:

- Phỏng vấn sâu:

+ 02 Bác sĩ trưởng khoa

+ 07 Điều dưỡng trưởng khoa

- Thảo luân nhóm: Thức hiên được 01 cuôc thảo luận nhóm với 05 điêu dưỡng trưởng của tham gia.

\subsection{Phương pháp và công cụ thu thập} số liệu

2.5.1. Công cụ thu thập số liệu phương pháp định lượng. Phiếu phỏng vấn định lượng: Thực trạng năng lực quản lý cho đối tượng điều dưởng trưởng khoa làm việc tại 05 Bệnh viện tuyển tỉnh Lào Cai được xây dựng dựa trên các tài liệu về quản lý điều dưỡng của Bộ Y tế, Quản lý và lãnh đạo hiệu quả của Hội Điều dưỡng Việt nam; Quy định chức năng nhiệm vụ của Điều dưỡng trưởng khoa tại Thông tư số 07/2011/TTBYT Hướng dẫn công tác điều dưỡng về chăm sóc người bệnh trong bệnh viện của Bộ Y tế.

Phương pháp thu thập số liệu: phiếu tự điền được phát cho ĐDTK mồi người 1 phiếu tự điền được thiết kế sẵn.

+ Sau khi phát vấn xong, ĐTV kiểm tra lại và đảm bảo các nội dung trong bảng phát vấn đã đầy đủ theo yêu cầu nghiên cứu.

+ ĐTV là các cán bộ của phòng Nghiệp vụ Y của Sở Y tế Lào Cai đã được tập huấn thổng nhất cách điều tra.

Hướng dẫn phỏng vấn sâu: Bao gồm các câu hỏi về năng lực quản lý cho dành các đối là điều dưỡng trưởng khoa và lãnh đạo phòng điêu dưỡng.

Hướng dẩn thảo luận nhóm: Thảo luận nhóm với lãnh đạo khoa, lãnh đạo khoa điều dưỡng và đại diện của các điều dưỡng trưởng khoa lâm sàng.

2.6. Phân tích số liệu. Số liệu định lượng được nhập bằng phần mềm Epidata 3.1 và được xử lý bằng phần mềm SPSS 18.0.

Số liệu định tính được gõ̃, đánh máy dưới dạng văn bản Word. Nghiên cứu viên đọc nội dung các cuộc phỏng vấn sâu để mã hóa thông tin.

Phương pháp phân tích theo chủ đề được áp dụng. Kết quả phân tích thông tin định tính nhằm 
bổ sung, giải thích cho kết quả định lượng. Một số thông tin do đối tượng nghiên cứu cung cấp được trích dẫn, minh họa cho kết quả nghiên cứu.

2.7. Biến số nghiên cứu. Trong nghiên cứu định lượng nhóm biến số bao gồm:

- Nhóm biến số về thông tin đối tượng nghiên cứu: 10 biến số về thông tin cá nhân của ĐDT.

- Nhóm biến số về thực hành quản lý điều dưỡng: 15 biến số kiến thức quản lý điều dưỡng của ĐDT.

Các chủ đề nghiên cứu định tính bao gồm:

- Thông tin chung về tình hình nhân lực và chất lượng làm việc của điều dưỡng trưởng tại các bệnh viện.

- Thông tin về một số yếu tố quản lý trong công việc của điêuu dưỡng trưởng tại các bệnh viện.

- Thông tin về các ảnh hưởng đến năng lực quản lý và giải pháp để nâng cao chất lượng của đội ngũ điều dưỡng trưởng tại các bệnh viện tuyến tỉnh.

2.8. Tiêu chí đánh giá. Đánh giá "Mức độ đủ khả năng đáp ứng và chưa đủ khả năng đáp ứng" thông qua các tiểu mục tự đánh giá mức độ tự tin của hoàn thành công viềc

-Thang điểm Likert 5 mức độ (1: Rất không

\section{KẾT QUẢ NGHIÊN CỨU}

\section{Bảng 3.2. Công tác chăm sóc người bệnh}

\begin{tabular}{|c|c|c|c|c|c|}
\hline \multirow{2}{*}{ Nội dung } & \multicolumn{2}{|c|}{ Đáp ứng } & \multicolumn{2}{|c|}{ Chưa đáp ứng } & \multirow{2}{*}{ Tổng } \\
\hline & $\mathbf{N}$ & $\%$ & $\mathbf{N}$ & $\%$ & \\
\hline $\begin{array}{l}\text { Khả năng quản lý tình trạng bệnh và tâm lý } \\
\text { cúa tưng người bệnh trong khoa }\end{array}$ & 7 & 13,0 & 47 & 87,0 & 54 \\
\hline $\begin{array}{l}\text { Khả năng tổ chức công tác chăm sóc đáp ứng } \\
\text { các nhu cầu cho người bệnh }\end{array}$ & 4 & 7,4 & 50 & 92,6 & 54 \\
\hline $\begin{array}{c}\text { Khả năng tổ chức thực hiện có hiệu quả chỉ } \\
\text { định điều trị của bác sĩ }\end{array}$ & 19 & 35,2 & 35 & 64,8 & 54 \\
\hline $\begin{array}{l}\text { Thực hiện đầy đủ các kỹ thuật điều dưỡng } \\
\text { được các nhân viên tuân thủ đây đủ }\end{array}$ & 22 & 40,7 & 32 & 59,3 & 54 \\
\hline $\begin{array}{l}\text { Thực hiện đây đủ các quy chế, quy định } \\
\text { chuyên môn được tuân thủ nghiêm túc }\end{array}$ & 22 & 40,7 & 32 & 59,3 & 54 \\
\hline
\end{tabular}

Bảng 3.7. cho thây tỉ lệ điều dưỡng trưởng xác nhận năng lực thực hiện đầy đủ các kỹ thuật điều dưỡng được các nhân viển tuân thủ đầy đủ và năng lực thực hiện đầy đủ các quy chế, quy định chuyên mổn được tuân thủ nghiêm túc là cao nhất $(40,7 \%)$, các năng lực tổ chức thực hiện có hiệu quả chỉ định điều trị của bác sĩ, tổ chức công tác chăm sóc đáp ứng các nhu cầu cho người bệnh, quản lý tình trạng bệnh và tâm lý của từng người bệnh trong khoa có tỉ lệ thấp hơn lần lượt là $35,2 \%, 7,4 \%$ và $13,0 \%$.

\section{Bảng 3.3. Triên khai nhiệm vụ đôî với nhân viên}

\begin{tabular}{|c|c|c|c|c|c|}
\hline \multirow{2}{*}{ Nội dung } & \multicolumn{3}{|c|}{ Đáp ứng } & \multicolumn{3}{|c|}{ Chưa đáp ứng } & \multirow{2}{*}{ Tổng } \\
\cline { 2 - 6 } & $\mathbf{N}$ & $\mathbf{\%}$ & $\mathbf{N}$ & $\mathbf{\%}$ & \\
\hline $\begin{array}{c}\text { Khả năng thuyết trình, xây dựng môi trường làm việc có đạo } \\
\text { đức và ứng xử chuyên mồn cho nhân viên dưới quyền }\end{array}$ & 12 & 22.2 & 42 & 77.8 & 54 \\
\hline $\begin{array}{c}\text { Khả năng nhận biê̂t năng lực của từng nhân viên để phân } \\
\text { công cônng việc phù hợp với khả năng của từng cá nhân }\end{array}$ & 18 & 33.3 & 36 & 66.7 & 54 \\
\hline Khả năng đào tạo và tạo điều kiện cho nhân viên học tập & 17 & 31.5 & 37 & 68.5 & 54 \\
\hline
\end{tabular}




\begin{tabular}{|c|c|c|c|c|c|}
\hline nâng cao trình độ chuyên môn và kỹ năng thành thạo tay nghề & & & & & \\
\hline $\begin{array}{l}\text { Khả năng đánh giá việc hoàn thành nhiệm vụ chuyên môn và } \\
\text { cách thức thực hiện cồng việc của từng nhân viên dưới quyền }\end{array}$ & 14 & 25.9 & 40 & 74.1 & 54 \\
\hline Khả năng bào vệ nhân viên trong cơ quan và trước người ngoài & 16 & 29.6 & 38 & 70.4 & 54 \\
\hline
\end{tabular}

Bảng 3.8. cho thấy tỉ lệ điều dưỡng trưởng xác nhận nhận biết năng lực của từng nhân viên để phân công công việc phù hợp với khả năng của từng cá nhân là $33,3 \%$, năng lực đào tạo và tạo điều kiện cho nhân viên học tập nâng cao trình độ chuyên môn và kỹ năng thành thạo tay nghề là $31.5 \%$, các năng lực còn lại như bảo vệ nhân viên trong cơ quan và trước người ngoài là $29,6 \%$, các năng lực còn lại đánh giá khá thấp ở mức dưới $25 \%$ như khả năng thuyết trình, xây dựng môi trường làm việc có đạo đức và ứng xử chuyên môn cho nhân viên dưới quyền và đánh giá việc hoàn thành nhiệm vụ chuyên môn và cách thức thực hiện công việc của từng nhân viên dưới quyền.

Bảng 3.4. Năng lực quản lý khoa/phòng

\begin{tabular}{|c|c|c|c|c|c|}
\hline \multirow{2}{*}{ Nội dung } & \multicolumn{2}{|c|}{ Đáp ứng } & \multicolumn{2}{|c|}{ Chưa đáp ứng } & \multirow{2}{*}{ Tổng } \\
\hline & $\mathbf{N}$ & $\%$ & $\mathbf{N}$ & $\%$ & \\
\hline $\begin{array}{l}\text { Quản lý chuyên môn: bảo đảm các quy chế, các chính sách, } \\
\text { các quy trình chuyên môn được mọi người tuân thủ }\end{array}$ & 12 & 22,2 & 42 & 77,8 & \\
\hline $\begin{array}{c}\text { Quản lý nhân lực: Bảo đảm nguồn lực của khoa sử dụng hiệu } \\
\text { quả, đúng vị trí }\end{array}$ & 18 & 33,3 & 36 & 66,7 & \\
\hline $\begin{array}{l}\text { Quản lý cơ sở hạ tầng, trang thiết bị, vật tư tiêu hao: Bảo } \\
\text { đảm các nguồn lực được sử dụng đúng mục đích, hiệu quả }\end{array}$ & 23 & 42,6 & 31 & 57,4 & \\
\hline $\begin{array}{c}\text { Quản lý môi trường làm việc: Bảo đảm khoa/phòng luôn sạch } \\
\text { đẹp, gọn gàng; bảo đảm an toàn cho người bệnh và nhân } \\
\text { viên y tế }\end{array}$ & 18 & 33,3 & 36 & 66,7 & \\
\hline $\begin{array}{l}\text { Quản lý y đức và văn hóa phục vụ: Taoo dựng được môi } \\
\text { trường phục vụ người bệnh có văn hóa và có y đức }\end{array}$ & 18 & 33,3 & 36 & 66,7 & \\
\hline
\end{tabular}

Bảng 3.9. cho thấy về nhóm năng lực quản lý khoa/phòng tỉ lệ điều dưỡng trưởng xác nhận nhận có năng lực quản lý cơ sở hạ tầng, trang thiết bị, vật tư tiêu hao: Bảo đảm các nguồn lực được sử dụng đúng mục đích, hiệu quả là cao nhất $(42,6 \%)$, các năng lực như: Bảo đảm nguồn lực của khoa sử dụng hiệu quả, đúng vị trí, bảo đảm khoa/phòng luôn sạch đẹp, gọn gàng; bảo đảm an toàn cho người bệnh và nhân viên y tế, tạo dựng được môi trường phục vụ người bệnh có văn hóa và có y đức đều ở mức $33,3 \%$ và thấp nhất là năng lực bảo đảm các quy chế, các chính sách, các quy trình chuyên môn được mọi người tuân thủ 22,2\%.

Bảng 3.5. Năng lực quản lý chung của Điều dướng trưởng khoa

\begin{tabular}{|c|c|c|c|c|c|}
\hline \multirow{2}{*}{ Nội dung } & \multicolumn{2}{|c|}{ Chưa đáp ứng } & \multicolumn{2}{c|}{ Đáp ứng } & \multirow{2}{*}{ Tổng } \\
\cline { 2 - 5 } & $\mathbf{N}$ & $\mathbf{\%}$ & $\mathbf{N}$ & $\mathbf{\%}$ & \\
\hline Năng lực quản lý chung & 23 & 42.6 & 31 & 57.4 & 100.0 \\
\hline
\end{tabular}

Kết quả tại bảng 3.10. cho thấy năng lực quản lý chung của 54 điều dưỡng trưởng tham gia nghiên cứu thì chỉ có $57,4 \%$ xác nhận đạt về năng lực quản lý chung, vẫn còn $42,6 \%$ xác nhận chưa đạt năng lực quản lý chung.

Một số yếu tố ảnh hưởng đến năng lực quản lý của điêu dưỡng trưởng

Trình độ cá nhân được xác định là một trong những yếu tố ảnh hưởng đến năng lực quản lý của điều dưỡng trưởng bệnh viện

"Một số điều dưỡng trưởng có trình độ trung cấp tưy có thâm niên công tác lâu năm nhưng khả năng tiếp cận công nghệ thông tin còn hạn chế, các điều dưỡng trưởng khoa có trình độ trung cấp do thâm niên công tác ngắn thì kỹ năng quản lý còn yếu" (PVS BS Trưởng khoa 01)
"Tuy một số điều dưỡng trưởng có năng lực chuyên mồn tốt, vượt trội tại khoa được lãnh đạo cất nhắc lên làm điều dưỡng trưởng, nhưng khả năng quản lý thì chưa được như yêu câu" (TNL, nữ 31 tuổi)

Hầu hết điều dưỡng trưởng cho rằng do các công việc tại khoa phòng còn nhiều, nên ảnh hưởng đến công tác quản lý của mình. Việc quá tải bệnh nhân tại một số khoa, như nội ngoại, sản số lượng bệnh nhân tăng vọt. Là điều dưỡng trưởng vừa phải quản lý chăm sóc người bệnh, quản lý nhân viên và quản lý khoa phòng nên dẫn đến sự quá tải trong công việc. Để làm trọn vẹn các công việc trên đòi hỏi người điều dưỡng trưởng phải bỏ nhiều thời gian và công sức hơn.

"Công việc rất nhiều, quản lý điều dưỡng viên, lập kế hoạch, như khoa mình điều dưỡng 
trưởng vẫn phải trực tiếp chăm sóc người bệnh nhiều, nên nhiều công việc quản lý chỉ làm được vào lúc rỗi và hoàn thành chủ yếu vào những hôm trực đêm"(PVS Điêuu dưỡng trưởng 02)

"Cồng việc rất bận, nên nhiều khi gặp khó khăn ở đâu thì hỏi bạn bè đồng nghiệp để giải quyết vấn đề thôi, nhưng thật sự là nhiều công việc giải quyết bằng kinh nghiệm nên chưa thật sự hiệu quả"(TNL, nữ 31 tuổi)

"Mình gần như' không có thời gian tự học, tìm hiểu thêm các kỹ năng về quản lý điều dưỡng" (TNL, nam 40 tuổi)

Một số yếu tố ảnh hưởng khác cũng được đề cập như phối hợp giữa bác sĩ trưởng khoa và điều dưỡng trưởng, quy trình quy hoạch, đào tạo và bổ nhiệm vẫn còn một số bất cập

"Bác sĩ chưa ủng hộ do còn ăn sâu quan niệm trong các bệnh viện. Bác sĩ luôn là người lãnh đạo, là người đứng đầu - còn điều dưỡng là người phục vụ, người phục tùng. Nên trong nhiều vấn đề, người điều dưỡng trưởng chưa thể phát huy được vai trò quản lý của mình..."(TNL, nam 40 tuổi)

"Điều dưỡng trưởng và bác sĩ là nguồn lực chính trong sứ mệnh phát triển bệnh viện đẩy, nhưng người điều dưỡng trưởng vẫn chưa có tiếng nói trong ở một số khoa" (PVS Điều dưỡng trưởng 03)

"Cách thức lựa chọn điều dưỡng trưởng vẫn theo kiểu truyền thống, người điều dưỡng trưởng được quy hoạch trong 1 thời gian ngắn, nhưng lại không được đào tạo, bồi dưỡng năng lực quản lý từ trước" (PVS Điêuu dưỡng trưởng 04)

"2 năm gần đây việc quy hoạch điều dưỡng trưởng đã có tiêu chí rõ ràng, nhưng chưa có ý nghĩa nhiều bởi phần lớn các điều dưỡng trưởng tại các khoa là do phân công, sắp xếp trong các giai đoạn trước" (PVS Trưởng khoa 05)

"Điều dưỡng trưởng được trao quyền nhiều hơn nhưng vẫn chưa được trao quyên quyết định tại khoa nên nhiêu khi xảy ra tình trạng báo cáo công việc phát sinh vượt cấp mà ko qua điều dưỡng trưởng, làm điều dưỡng trưởng không nắm bắt được thông tin để kịp thời xử lý ngay tại khoa" (PVS Điêu dướng trưởng 03)

Công tác đào tạo, giám sát cũng chưa được thực hiện tốt ở nhiều đơn vị.

\section{BÀN LUẬN}

Công tác chăm sóc người bệnh: Đánh giá về năng lực quản lý trong công tác chăm sóc người bệnh thì khả thực hiện đầy đủ các kỹ thuật điều dưỡng được các nhân viên tuân thủ điêu trị và khả năng thực hiện đầy đủ các quy chế, quy định chuyên môn được tuân thủ nghiêm túc là cao nhất $40,7 \%$, tiếp theo đến là khả năng tổ chức thực hiện có hiệu quả chỉ định điều trị của bác sĩ là $35,2 \%$.

Năng lực triển khai nhiệm vụ đối với nhân viên: Đối với 05 khả năng trong lĩnh vực triển khai nhiệm vụ với nhân viên, kết quả nghiên cứu đã chỉ ra rằng khả năng nhận biết năng lực của từng nhân viên để phân công công việc phù hợp với khả năng của từng cá nhân là cao nhất $33,3 \%$; tiếp theo khả năng đào tạo và tạo điêu kiện cho nhân viên học tập nâng cao trình độ chuyên môn và kỹ năng thành thạo tay nghề lại chiếm tỷ lệ là $31,5 \%$, Khả năng đánh giá việc hoàn thành nhiệm vụ chuyên môn và cách thực hiện công việc của từng nhân viên dưới quyền là $25,9 \%$. Trong khi đó với vai trò là Điều dưỡng trưởng khoa, nhưng khả năng đánh giá hoàn thành nhiệm vụ chuyên môn và cách thức thực hiện công việc của từng nhân viên dưới quyền cũng chỉ ở mức $25,9 \%$, khả năng thuyết trình, xây dựng môi trường làm việc có đạo đức và ứng xử chuyên môn cho nhân viên dưới quyền đạt ở mức thấp nhất là 22,2\%. Các kết quả trên có sự khác biệt khi so sánh với nghiên cứu về năng lực của điều dưỡng trưởng khoa của Nguyễn Vính Thái tại Nha trang.

Theo kết quả nghiên cứu định tính cho thấy, do thiếu nhân lực nên nhiều cán bộ được sắp xếp làm điều dưỡng trưởng nhưng vẫn chưa phù hợp với trình độ chuyên môn, tuy có kinh nghiệm trong chuyên môn điều dưỡng nhưng khả năng quản lý còn hạn chế, còn nhiều trở ngại trong công tác. Ngoài ra vì bệnh nhân đông nên nhiều điều dưỡng trưởng còn làm việc kiêm nhiệm nên cũng có ảnh hưởng đến khả năng quản lý. Điều này khá phù hợp với nghiên cứu của Dương Thị Thanh Huyền tại Nam Định (2019) khi cho biết khối lượng khối lượng công việc nhiêu cũng tạo áp lực lớn cho điều dưỡng điều dưỡng trưởng và làm cho điều dưỡng trưởng có ít thời gian dành cho công tác quản lý hơn

Trong thực tế nghiên cứu tại vẫn còn tồn tại quan điểm cho rằng: "Bác sĩ là người đứng đầu và quan trong nhất tại các bệnh viện, còn điêu dưỡng chỉ là người tuân thủ và người phục vụ cho bác sĩ". Mặc dù người điều dưỡng trưởng có vị thế trong cổng tác cao hơn điều dưỡng viên, nhưng trong mối quan hệ công việc với bác sĩ cũng vẫn có vị thế kém hơn tại một số khoa phòng chuyên môn. Việc thiếu sự ủng hộ, hợp tác của bác sĩ làm cho điều dưỡng trưởng khó khăn trong công tác quản lý khoa phòng và phát huy hết khả năng chuyên môn quản lý. Kết quả 
nghiên cứu cũng tương đồng với các nghiên cứu khác liên quan đến hoạt động của điều dưỡng trong mối quan hệ với đồng nghiệp trong bệnh viện.

\section{KẾT LUÂN}

Tỷ lệ Điều dưỡng trưởng khoa đủ năng lực quản lý chung vẫn ở mức trung bình là $57,4 \%$, trong đó các năng lực yếu nhất là quản lý chuyên môn, tiếp theo đó là quản lý nguồn nhân lực, quản lý y đức và văn hoá phục vụ, quản lý môi trường làm việc, mặc dù năng lực quản lý cơ sở hạ tầng có kết quả cao nhất nhưng cũng chỉ chiếm $42,6 \%$

\section{TÀI LIỆU THAM KHẢO}

1. Bộ Y Tế. Chuẩn năng lực cơ bản của Điều dưỡng Việt Nam, (2012).

2. Bộ Y Tế. Tài liệu Quản lý Điều dưỡng. Hà Nội: Nhà xuất bản Y Học; 2004.
3. Sở Y tế Lào Cai. Báo cáo nhân lực y tế tỉnh Lào Cai năm 2019. Lào Cai: 2019.

4. Bùi Thị Bích Ngà. Thực trạng công tác chăm sóc của điểu dưỡng qua nhận xét của người bệnh điều trị nội trú tại bệnh viển $Y$ học cô truyền Trung ương năm 2011. Hà Nội: Trường Đại học Y tế công cộng; 2011

5. Tỉnh ủy Lào Cai. Đề án 7- Đề án Phát triển y tế, chăm sóc và nâng cao sức khỏe nhân dân, giai đoan 2016 - 2020. Lào Cai: 2015.

6. Dương Thị Thanh Huyên. Đánh giá kết quả hoạt động quản lý của điều dưỡng trưởng tai các cơ sở y tế tuyến huyên tỉnh Nam Định năm 2019. Tạp chí Khoa hoc Điếu dưỡng. 2019; 3(2):76-85.

7. Dương Thị Bình Minh. Thực trạng công tác chăm sóc điêuu dưỡng người bệnh tại các khoa lâm sàng bênh viên Hữu nghị Tạp chí $Y$ học thực hành. 2013;876(7):125-9.

8. Bùi Thị Bích Ngà. Thực trang công tác chăm sóc của điều dưỡng qua nhân xét của người bệnh điều trị nội trú tại bệnh viển $Y$ học cố truyền Trung ương năm 2011. Hà Nội: Trường Đại học Y tế công cộng; 2011.

\section{ĐĂC ĐIỂM LÂM SÀNG, CÂN LÂM SÀNG Ở BÊNNH NHI BỊ RẮN CHÀM QUẠP CẮN TẠI BỆNH VIỆN NHI ĐỒNG 1}

\section{TÓM TẮT}

Mục tiêu: Xác đinh đặc điểm lâm sàng và cận lâm sàng ở bệnh nhi bị rẳn chàm quạp cắn nhập Bệnh viện Nhi đồng 1 . Phương pháp nghiên cứu: Nghiên cứu hàng loạt ca trên 54 trẻ bi rắn chàm quạp cắn nhập khoa Cấp cứu, Bệnh viện Nhi đồng 1 từ ngày $01 / 01 / 2011$ đến ngày $31 / 12 / 2020$. Kết quả: Gần $100 \%$ trường hợp sưng nề và đau tại chố, dấu móc độc $72,2 \%$. Tỉ lệ nhiễm trùng và hoại tử vết thương khá cao $(37,0 \%$ và $38,9 \%)$. 44,4\% xuất hiên bóng nước và khi có bóng nước thì $100 \%$ có xuất huyết trong bóng nước. Có mối tương quan giữa bóng nước, nhiễm trùng, hoai tử với mức đô nhiễm độc ( $\mathrm{p}<$ $0,001)$. Bầm máu $55,6 \%$, chảy máu vết cắn $46,3 \%$, xuất huyết da $46,3 \%$, chảy máu nướu răng $14,8 \%$, xuất huyết tiêu hóa $1,9 \%$, thiểu niệu $(1,9 \%)$, hạ huyết áp $(1,9 \%)$ chủ yếu gặp ở bênh nhân nhiễm đọ̉ nặng. Có mối tương quan giữa bẩm máu, chảy máu vết cắn, xuất huyết da với mức độ nhiếm độc ( $\mathrm{p}<$ 0,001). Vết thương lan rộng qua 2 khớp 55,5\%. Rối loan chức năng đông máu là biểu hiện thường gặp $94,6 \%$, trong đó DIC chiếm 57,5\% với fibrinogen giám < $1 \mathrm{~g} / \mathrm{L}(59,3 \%)$, PT kéo dài $(53,7 \%)$, INR > 1,5 $(46,3 \%)$, tiểu câu giảm $<150.000 / \mathrm{mm}^{3}(40,7 \%)$, aPTT kéo dài $(35,2 \%)$. Sự thay đổi xét nghiệm chức

*Bệnh viện Đa khoa Trung tâm Tiền Giang

Chịu trách nhiệm chính: Nguyễn Thành Nam

Email: thanhnam@pediatrician.vn

Ngày nhận bài: 17.3.2021

Ngày phản biên khoa hoc: 13.5.2021

Ngày duyệt bài: 19.5.2021

\section{Nguyễn Thành Nam*, Tạ Văn Trầm*}

năng đông máu và mức độ nhiễm độc có mối tương quan có ý nghĩa thống kê, $p<0,001$. Kết luận: Ớ những bệnh nhân có độ sưng nề vết thương lan rộng qua 2 khớp có tỉ lệ nhiễm độc mức độ nặng cao gấp 2,8 lần (KTC 95\%: 1,5 - 5,1), sự khác biệt có ý nghĩa thống kê, $p<0,001$

Tư khóa: rắn cắn, rắn chàm quạp, huyết thanh kháng nọc rắn.

\section{SUMMARY}

CLINICAL AND SUBCLINICAL

CHARACTERISTICS OF CHILDREN WITH MALAYAN PIT VIPER BITES HOSPITALIZED IN CHILDREN HOSPITAL 1

Objectives: Determination of clinical and subclinical characteristics of children with malayan pit viper bites hospitalized in Children hospital 1 . Methods: Descriptive study was conducted on 54 medical records of children with snake bites hospitalized in Children hospital 1 from 01/01/2011 to $31 / 12 / 2020$. Results: Nearly $100 \%$ of cases of swelling and pain immediately, toxic hook marks $72.2 \%$. The incidence of infection and wound necrosis was quite high (37.0\% and $38.9 \%$ ). $44.4 \%$ appeared blisters and when there were blisters, $100 \%$ had hemorrhages in blisters. There is a correlation between blisters, infections, necrosis with the degree of intoxication ( $p<0.001$ ). $55.6 \%$ bruising, $46.3 \%$ bleeding, $46.3 \%$ skin hemorrhaging, gum bleeding $14.8 \%$, digestive bleeding $1.9 \%$, oliguria $(1.9 \%)$, lowering blood pressure $(1.9 \%)$ mainly seen in patients with severe infection. There is a correlation between bruising, bite bleeding, skin hemorrhage with 